Article

\title{
Cerebral Hyperperfusion after Revascularization Inhibits Development of Cerebral Ischemic Lesions Due to Artery-to-Artery Emboli during Carotid Exposure in Endarterectomy for Patients with Preoperative Cerebral Hemodynamic Insufficiency: Revisiting the "Impaired Clearance of Emboli" Concept
}

\author{
Kentaro Fujimoto ${ }^{1}$, Yoshiyasu Matsumoto ${ }^{1}$, Kohki Oikawa ${ }^{1}$, Jun-ichi Nomura ${ }^{1}$,

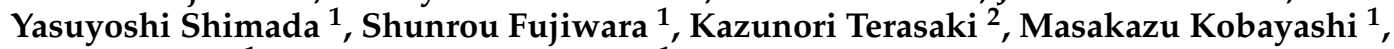 \\ Kenji Yoshida ${ }^{1}$ and Kuniaki Ogasawara ${ }^{1, *}$ \\ 1 Department of Neurosurgery, School of Medicine, Iwate Medical University, 19-1 Uchmaru, \\ 020-8505 Morioka, Japan; norimori@iwate-med.ac.jp (K.F.); yoshiyasu.matumoto@gmail.com (Y.M.); \\ hchrt770@yahoo.co.jp (K.O.); pbx1vfuj@yahoo.co.jp (J.-i.N.); khata@iwate-med.ac.jp (Y.S.); \\ shunfuji@iwate-med.ac.jp (S.F.); kobamasa@iwate-med.ac.jp (M.K.); kenyoshi@iwate-med.ac.jp (K.Y.) \\ 2 Cyclotron Research Center, School of Medicine, Iwate Medical University, 19-1 Uchmaru, 020-8505 Morioka, \\ Japan; ktera@iwate-med.ac.jp \\ * Correspondence: kuogasa@iwate-med.ac.jp; Tel.: +81-19-651-5111; Fax: +81-19-625-8799
}

Academic Editor: Michael Henein

Received: 1 June 2016; Accepted: 25 July 2016; Published: 3 August 2016

\begin{abstract}
The purpose of the present study was to determine whether cerebral hyperperfusion after revascularization inhibits development of cerebral ischemic lesions due to artery-to-artery emboli during exposure of the carotid arteries in carotid endarterectomy (CEA). In patients undergoing CEA for internal carotid artery stenosis $(\geqslant 70 \%)$, cerebral blood flow $(\mathrm{CBF})$ was measured using single-photon emission computed tomography (SPECT) before and immediately after CEA. Microembolic signals (MES) were identified using transcranial Doppler during carotid exposure. Diffusion-weighted magnetic resonance imaging (DWI) was performed within $24 \mathrm{~h}$ after surgery. Of 32 patients with a combination of reduced cerebrovascular reactivity to acetazolamide on preoperative brain perfusion SPECT and MES during carotid exposure, 14 (44\%) showed cerebral hyperperfusion (defined as postoperative CBF increase $\geqslant 100 \%$ compared with preoperative values), and $16(50 \%)$ developed DWI-characterized postoperative cerebral ischemic lesions. Postoperative cerebral hyperperfusion was significantly associated with the absence of DWI-characterized postoperative cerebral ischemic lesions (95\% confidence interval, $0.001-0.179 ; p=0.0009)$. These data suggest that cerebral hyperperfusion after revascularization inhibits development of cerebral ischemic lesions due to artery-to-artery emboli during carotid exposure in CEA, supporting the "impaired clearance of emboli" concept. Blood pressure elevation following carotid declamping would be effective when embolism not accompanied by cerebral hyperperfusion occurs during CEA.
\end{abstract}

Keywords: artery-to-artery embolism; carotid endarterectomy; cerebral hemodynamic insufficiency; cerebral hyperperfusion; ischemic lesion 


\section{Introduction}

It has been previously reported that hemodynamic and embolic mechanisms are closely linked, and they may act together to cause cerebral ischemia [1,2]. The authors suggested that clearance of emboli from a proximal lesion may be decreased by low blood flow velocity in a cerebral artery, which may lead to ischemia from emboli in poorly perfused areas of the brain. In support of this, several previous studies showed that there was a relationship between embolic and hemodynamic mechanisms, particularly in border zone regions having impaired wash-out due to artery-to-artery embolism in cases of middle cerebral artery stenosis $[3,4]$ or in new postoperative neurological deficits caused by emboli developing during carotid artery stenting associated with intraprocedural lower middle cerebral artery blood flow velocity [5].

More than $70 \%$ of the intraoperative procedure-related strokes that occur during carotid endarterectomy (CEA) are due to surgical site embolisms [6]. When intraoperative transcranial Doppler (TCD) is used to monitor the middle cerebral artery (MCA), more than $90 \%$ of patients undergoing CEA are found to have microembolic signals (MES) [6-8]. However, the stage of CEA determines the quality and quantity of MES that are detected $[6,8,9]$. When the carotid arteries are being exposed, plaque that has not been removed is exposed to blood flow and can be a source of emboli. In such cases, emboli can be dislodged from the surgical site into the intracranial arteries during manipulation of the carotid arteries [8]. In addition, the MES that are detected are considered to represent solid masses, because the target vessel is closed while the vessel is being exposed [10]. However, once the carotid artery walls are incised for the endarterectomy, many harmless gaseous MES may be seen during carotid declamping as air enters the arterial lumina $[8,11]$. MES detection while the artery is being exposed has been shown to be correlated with the development of post-CEA cerebral ischemic lesions on diffusion-weighted imaging (DWI) [7-9,11-13]. Furthermore, these ischemic lesions that are related to the emboli generated during carotid artery exposure have been shown to be related to preoperative hemodynamic cerebral compromise, such as reduced cerebrovascular reactivity (CVR) to acetazolamide [14], providing support for the concept of "impaired clearance of emboli".

Cerebral hyperperfusion is defined as a major increase in ipsilateral cerebral blood flow (CBF) after surgical repair of carotid stenosis that is well above the metabolic demands of the brain tissue; it is another adverse event following CEA [15]. It occasionally evolves into cerebral hyperperfusion syndrome, whose characteristic manifestations include face and eye pain, unilateral headache, seizure, focal neurological symptoms, and disturbance of consciousness secondary to intracerebral hemorrhage or cerebral edema [15-18]. Impairment of the cerebral hemodynamic reserve before surgery may be related to post-CEA hyperperfusion, and quick normalization of perfusion pressure after CEA may produce hyperperfusion in brain regions with diminished autoregulation from chronic ischemia $[17,18]$. This hypothesis is consistent with the observation that reduced CVR to acetazolamide prior to surgery is a significant predictor of hyperperfusion after CEA [19-21].

Thus, both cerebral ischemic lesions due to artery-to-artery embolism and cerebral hyperperfusion may develop simultaneously during CEA in patients with preoperative cerebral hemodynamic impairment. When broadening the interpretation of the "impaired clearance of emboli" concept, blood flow greater than the normal level can inhibit development of ischemic lesions due to emboli in the brain, and research regarding the influence of cerebral hyperperfusion on the development of cerebral ischemic lesions due to artery-to-artery embolism seems interesting from the standpoint of this concept.

The aim of the present study was to determine whether broadening the interpretation of the "impaired clearance of emboli" concept is correct, namely cerebral hyperperfusion after revascularization inhibits development of cerebral ischemic lesions due to intraoperative artery-to-artery emboli. In order to do this, the relationship between development of DWI-characterized postoperative cerebral ischemic lesions and cerebral hyperperfusion was investigated in patients with a combination of preoperatively reduced CVR to acetazolamide on brain perfusion single-photon emission computed tomography (SPECT) and MES on TCD during carotid artery exposure in CEA. 


\section{Results}

\subsection{Trial Profile}

Figure 1 shows the patient flow chart for this study. Six hundred and thirty patients with ipsilateral internal carotid artery (ICA) stenosis $\geqslant 70 \%$ and useful residual function were scheduled for CEA and consented to participate in the present study. Of these 630 patients, 190 were defined as having reduced CVR to acetazolamide. Of these 190 patients, five did not undergo CEA and were excluded from the analysis. Of the 185 patients who underwent CEA, 23 did not show reliable TCD monitoring during carotid exposure because of failure to obtain an adequate bone window, and 26 showed electroencephalography (EEG)-defined hemispheric ischemia during ICA clamping; these 47 patients (two had both conditions) were excluded from the analysis. Of the remaining 138 patients, 32 had MES during exposure of the carotid arteries and were finally analyzed. Data acquisition with brain perfusion SPECT was completed within $3 \mathrm{~h}$ after declamping of the ICA in all these 32 patients. They all underwent DWI $24 \mathrm{~h}$ after surgery.

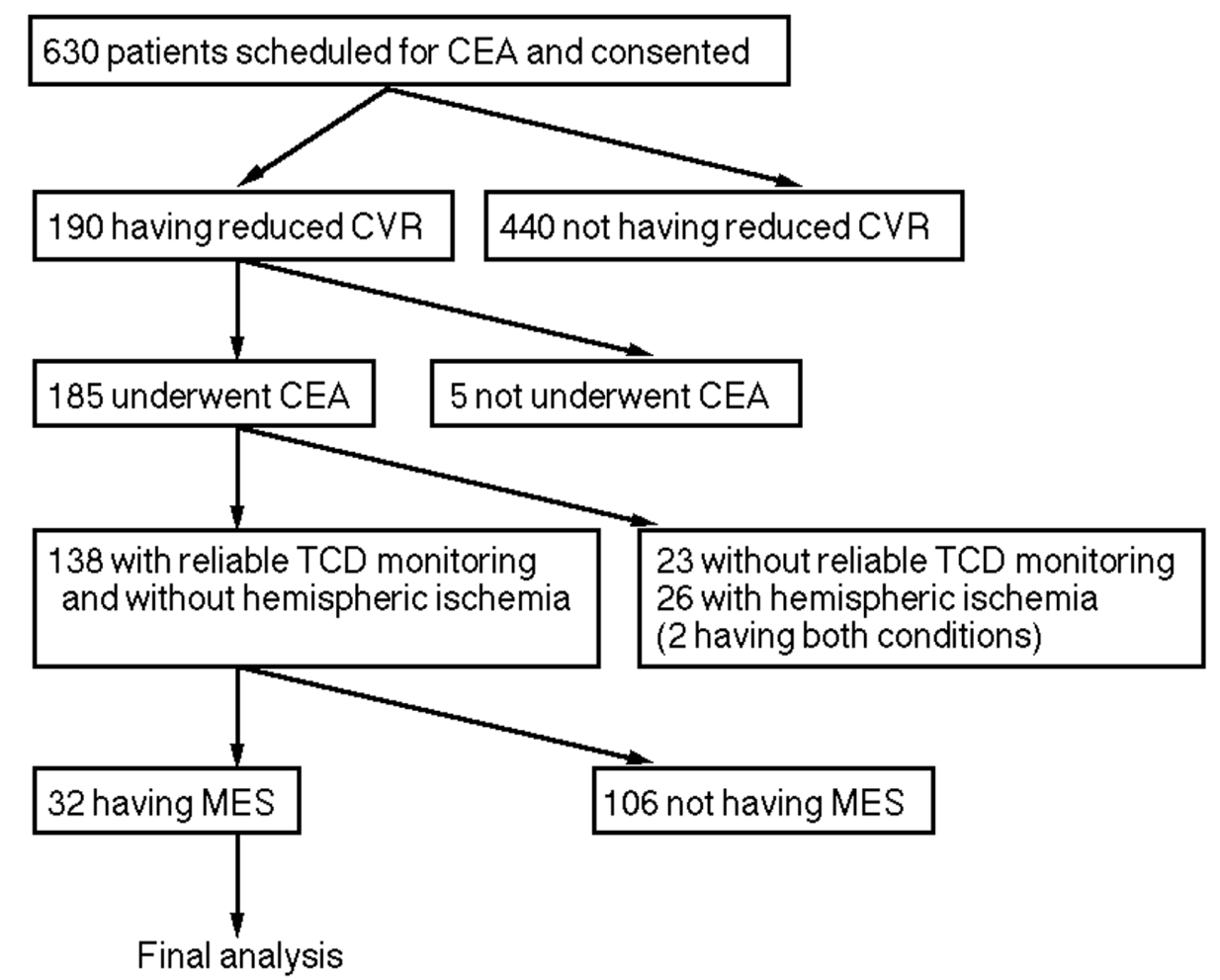

Figure 1. Trial profile showing the flow chart of patient numbers from initial screening to final analysis. Patients who did not have preoperative reduced cerebrovascular reactivity (CVR), did not undergo carotid endarterectomy (CEA), did not have reliable intraoperative transcranial Doppler (TCD) monitoring, had hemispheric ischemia during carotid clamping, and did not have microembolic signals (MES) during carotid exposure were excluded from the study.

\subsection{Clinical Characteristics}

The mean age of the 32 patients ( 29 men, three women) was $71.7 \pm 4.5$ (mean \pm standard deviation (SD)) years (range of 63-85 years). Twenty-six patients had preoperative hypertension, and 23 patients received antihypertensive drugs (calcium antagonist alone for five, angiotensin receptor blocker alone for 13 and both for five). Thirteen patients had preoperative diabetes mellitus, and all these patients received antidiabetic drugs. Fifteen patients had preoperative dyslipidemia, and 12 patients received a statin (strong statin for six). Seven patients had ischemic heart or valvular disease that did not satisfy the criteria for high-risk factors for CEA in the Stenting and Angioplasty with Protection in 
Patients at High Risk for Endarterectomy (SAPPHIRE) study (congestive heart failure, abnormal stress test, or need for open-heart surgery) [22]. None of the 32 patients had atrial fibrillation. Twenty-five patients had ipsilateral carotid territory symptoms, and seven patients had asymptomatic ICA stenosis. The overall average degree of ICA stenosis was $85.4 \% \pm 8.8 \%$ (range, $70 \%-99 \%$ ), with nine patients showing $>70 \%$ stenosis or occlusion in the contralateral ICA. Preoperative CBF and CVR to acetazolamide were $33.1 \pm 6.1 \mathrm{~mL} / 100 \mathrm{~g} / \mathrm{min}$ (range of $22.6-44.5 \mathrm{~mL} / 100 \mathrm{~g} / \mathrm{min}$ ) and $8.6 \% \pm 6.9 \%$ (range of $-8.3 \%-18.0 \%$ ), respectively. Preoperative systolic blood pressure was $133.6 \pm 11.7 \mathrm{mmHg}$ (range of 111-156 mmHg). The number of MES ranged from one to 14 (4.3 \pm 3.9 ). The interval from the first MES to ICA declamping ranged from 34 to $59 \mathrm{~min}(45.3 \pm 6.4 \mathrm{~min})$. The interval from the last MES to ICA declamping ranged from 35 to $65 \mathrm{~min}(46.8 \pm 6.6 \mathrm{~min})$. Mean systolic blood pressure during carotid exposure was $113.8 \pm 10.7 \mathrm{mmHg}$ (range of 95-138 $\mathrm{mmHg}$ ). Mean duration of ICA clamping was $36.0 \pm 5.7 \mathrm{~min}$ (range of $28-47 \mathrm{~min}$ ). Mean systolic blood pressure in the post-carotid declamping period in surgery was $121.4 \pm 11.9 \mathrm{mmHg}$ (range of $105-141 \mathrm{mmHg}$ ). Mean systolic blood pressure in the postoperative period (within $24 \mathrm{~h}$ after surgery) was $127.8 \pm 12.6 \mathrm{mmHg}$ (range of $109-147 \mathrm{mmHg}$ ). The mean rate of blood pressure-measured points with successfully controlled blood pressure to all measured points in the post-carotid declamping period in surgery was $85.9 \% \pm 3.9 \%$ (range of $72 \%-93 \%$ ). The mean rate of blood pressure-measured points with successfully controlled blood pressure to all the measured points in the postoperative period was $76.1 \% \pm 4.9 \%$ (range of $67 \%-92 \%)$.

\subsection{Postoperative Events}

In the 32 patients studied, postoperative CBF was $52.9 \pm 17.5 \mathrm{~mL} / 100 \mathrm{~g} / \mathrm{min}$ (range of 35.8-90.5 $\mathrm{mL} / 100 \mathrm{~g} / \mathrm{min}) ; 14$ patients $(44 \%)$ met CBF criteria for cerebral hyperperfusion. Sixteen patients $(50 \%)$ developed new postoperative ischemic lesions on DWI $24 \mathrm{~h}$ after surgery in the cortex and/or white matter in the cerebral hemisphere ipsilateral to CEA. All new ischemic lesions were spotty, and their diameters were $1 \mathrm{~cm}$ or less. Five (16\%) of 32 patients studied developed new neurological deficits after recovery from general anesthesia. All deficits included slight hemiparesis contralateral to the CEA. These deficits resolved completely within $12 \mathrm{~h}$ in these five patients, and they underwent additional DWI between 6 and $8 \mathrm{~h}$ after surgery and had new postoperative ischemic lesions on both the first ( 6 to $8 \mathrm{~h}$ after surgery) and second ( $24 \mathrm{~h}$ after surgery) postoperative DWI examinations.

\subsection{Postoperative Cerebral Hyperperfusion vs. Diffusion-Weighted Imaging (DWI)-Characterized Postoperative Cerebral Ischemic Lesions}

Results of univariate analyses of factors related to the development of DWI-characterized postoperative cerebral ischemic lesions are shown in Table 1. The postoperative CBF and the incidence of postoperative cerebral hyperperfusion were significantly higher in patients without than in those with DWI-characterized postoperative cerebral ischemic lesions. Other variables were not significantly associated with DWI-characterized postoperative cerebral ischemic lesions. After eliminating variables that were closely related, the following items with values of $p<0.2$ in univariate analyses were adopted as confounders in the logistic regression model for multivariate analysis: degree of ICA stenosis and postoperative CBF or postoperative cerebral hyperperfusion (since the latter two interacted, each item was adopted individually). This analysis showed that greater postoperative CBF (95\% confidence interval, $0.616-0.938 ; p=0.0104)$ or postoperative cerebral hyperperfusion ( $95 \%$ confidence interval, $0.001-0.179 ; p=0.0009$ ) was significantly associated with the absence of DWI-characterized postoperative cerebral ischemic lesions.

Figure 2 shows the relationships between the number of MES, postoperative CBF, cerebral hyperperfusion, and the development of DWI-characterized postoperative cerebral ischemic lesions. Postoperative $\mathrm{CBF}$ in patients with cerebral hyperperfusion ranged from mean $+3.9 \mathrm{SD}$ to mean $+11.8 \mathrm{SD}$ of the control value. Whereas $15(83 \%)$ of 18 patients without postoperative cerebral hyperperfusion showed DWI-characterized postoperative cerebral ischemic lesions, only one ( $7 \%$ ) of 14 patients with hyperperfusion had these ischemic lesions. 
Table 1. Univariate analysis of factors related to development of diffusion-weighted imaging (DWI)-characterized postoperative cerebral ischemic lesions.

\begin{tabular}{|c|c|c|c|}
\hline \multirow{3}{*}{ Variable } & \multicolumn{2}{|c|}{$\begin{array}{l}\text { DWI-Characterized } \\
\text { Ischemic Lesions }\end{array}$} & \multirow{3}{*}{$p$} \\
\hline & Yes & No & \\
\hline & $(n=16)$ & $(n=16)$ & \\
\hline Age (years, mean $\pm \mathrm{SD}$ ) & $72.8 \pm 5.4$ & $70.7 \pm 3.2$ & 0.2557 \\
\hline Male sex & $15(94 \%)$ & $14(88 \%)$ & $>0.9999$ \\
\hline Hypertension & $12(75 \%)$ & $14(88 \%)$ & 0.6539 \\
\hline Preoperative antihypertensive drugs & $10(63 \%)$ & $13(81 \%)$ & 0.4331 \\
\hline Preoperative calcium antagonist & $5(31 \%)$ & $5(31 \%)$ & $>0.9999$ \\
\hline Preoperative angiotensin receptor blocker & $8(50 \%)$ & $10(63 \%)$ & 0.7224 \\
\hline Diabetes mellitus & $6(38 \%)$ & $7(44 \%)$ & $>0.9999$ \\
\hline Preoperative antidiabetic drugs & $6(38 \%)$ & $7(44 \%)$ & $>0.9999$ \\
\hline Dyslipidemia & $7(44 \%)$ & $8(50 \%)$ & $>0.9999$ \\
\hline Preoperative statins & $5(31 \%)$ & $7(44 \%)$ & 0.7160 \\
\hline Preoperative strong statins * & $2(12 \%)$ & $4(25 \%)$ & 0.6539 \\
\hline Preoperative aspirin & $6(38 \%)$ & $4(25 \%)$ & 0.7043 \\
\hline Preoperative clopidogrel & $10(63 \%)$ & $12(75 \%)$ & 0.7043 \\
\hline Ischemic heart or valvular disease & $3(19 \%)$ & $4(25 \%)$ & $>0.9999$ \\
\hline Symptomatic lesion & $14(88 \%)$ & $11(69 \%)$ & 0.3944 \\
\hline Degree of ICA stenosis $(\%$, mean \pm SD) & $83.1 \pm 9.0$ & $87.7 \pm 8.2$ & 0.1258 \\
\hline Bilateral lesions & $4(25 \%)$ & $5(31 \%)$ & $>0.9999$ \\
\hline Preoperative CBF $(\mathrm{mL} / 100 \mathrm{~g} / \mathrm{min}$, mean $\pm \mathrm{SD})$ & $31.9 \pm 5.8$ & $34.4 \pm 6.4$ & 0.2581 \\
\hline Preoperative CVR to acetazolamide $(\%$, mean $\pm \mathrm{SD})$ & $8.7 \pm 5.9$ & $8.6 \pm 8.0$ & 0.6783 \\
\hline Preoperative systolic blood pressure $(\mathrm{mmHg}$, mean $\pm \mathrm{SD})$ & $134.5 \pm 15.8$ & $132.5 \pm 14.2$ & 0.9254 \\
\hline Number of MES (mean \pm SD) & $4.6 \pm 4.3$ & $4.0 \pm 3.6$ & 0.8932 \\
\hline Interval from first MES to ICA declamping (min, mean \pm SD) & $46.1 \pm 6.8$ & $44.4 \pm 6.1$ & 0.4848 \\
\hline Interval from last MES to ICA declamping (min, mean \pm SD) & $47.2 \pm 7.9$ & $46.3 \pm 5.2$ & 0.8353 \\
\hline $\begin{array}{l}\text { Mean systolic blood pressure during carotid exposure } \\
(\mathrm{mmHg}, \text { mean } \pm \mathrm{SD})\end{array}$ & $114.2 \pm 14.8$ & $113.4 \pm 13.0$ & 0.9849 \\
\hline Duration of ICA clamping (min, mean \pm SD) & $37.2 \pm 5.6$ & $34.8 \pm 5.6$ & 0.2191 \\
\hline $\begin{array}{l}\text { Mean systolic blood pressure after carotid declamping } \\
(\mathrm{mmHg} \text {, mean } \pm \mathrm{SD})\end{array}$ & $122.2 \pm 15.1$ & $120.7 \pm 13.1$ & 0.9049 \\
\hline $\begin{array}{l}\text { Successfully controlled blood pressure after carotid declamping ** } \\
(\% \text {, mean } \pm \text { SD })\end{array}$ & $84.6 \pm 5.3$ & $87.2 \pm 6.8$ & 0.8954 \\
\hline $\begin{array}{l}\text { Mean systolic blood pressure in postoperative period } \\
(\mathrm{mmHg}, \text { mean } \pm \mathrm{SD})\end{array}$ & $128.8 \pm 16.8$ & $127.1 \pm 17.0$ & 0.9241 \\
\hline $\begin{array}{l}\text { Successfully controlled blood pressure in postoperative period }{ }^{* * *} \\
(\% \text {, mean } \pm \mathrm{SD})\end{array}$ & $74.5 \pm 6.8$ & $78.3 \pm 7.8$ & 0.8037 \\
\hline Postoperative CBF $(\mathrm{mL} / 100 \mathrm{~g} / \mathrm{min}$, mean $\pm \mathrm{SD})$ & $39.6 \pm 4.8$ & $66.3 \pm 15.0$ & $<0.0001$ \\
\hline Cerebral hyperperfusion & $1(6 \%)$ & $13(81 \%)$ & $<0.0001$ \\
\hline
\end{tabular}

SD, Standard deviation; ICA, Internal carotid artery; CBF, Cerebral blood flow; CVR, Cerebrovascular reactivity; MES, Microembolic signal; *, Including atorvastatin, pitavastatin, and rosuvastatin; **, Rate of blood pressure-measured points with systolic blood pressure $<90 \%$ of the preoperative value in the post-carotid declamping period in surgery; ${ }^{* * *}$, Rate of blood pressure-measured points with systolic blood pressure $<90 \%$ of the preoperative value in the postoperative period (within $24 \mathrm{~h}$ after surgery). 


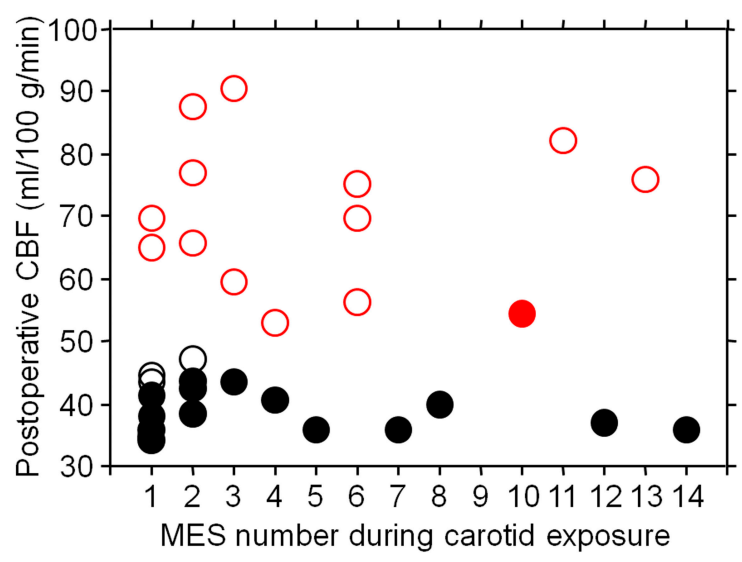

Figure 2. Relationships between the number of microembolic signals (MES), postoperative CBF (cerebral blood flow), cerebral hyperperfusion, and the development of diffusion-weighted imaging (DWI)-characterized postoperative cerebral ischemic lesions. Closed and open circles indicate patients with and without DWI-characterized postoperative cerebral ischemic lesions, respectively. Red and black circles indicate patients with and without postoperative cerebral hyperperfusion (defined as postoperative CBF increase $\geqslant 100 \%$ compared with preoperative values), respectively. Whereas 15 (83\%) of 18 patients without postoperative cerebral hyperperfusion showed DWI-characterized postoperative cerebral ischemic lesions, only one (7\%) of 14 patients with hyperperfusion had these ischemic lesions.

\subsection{Case Presentation}

Figure 3 shows images of brain perfusion SPECT, TCD, and DWI in a 74-year-old man with symptomatic ICA stenosis (90\%) showing DWI-characterized postoperative cerebral ischemic lesions due to MES during exposure of the carotid arteries despite development of cerebral hyperperfusion after left CEA.

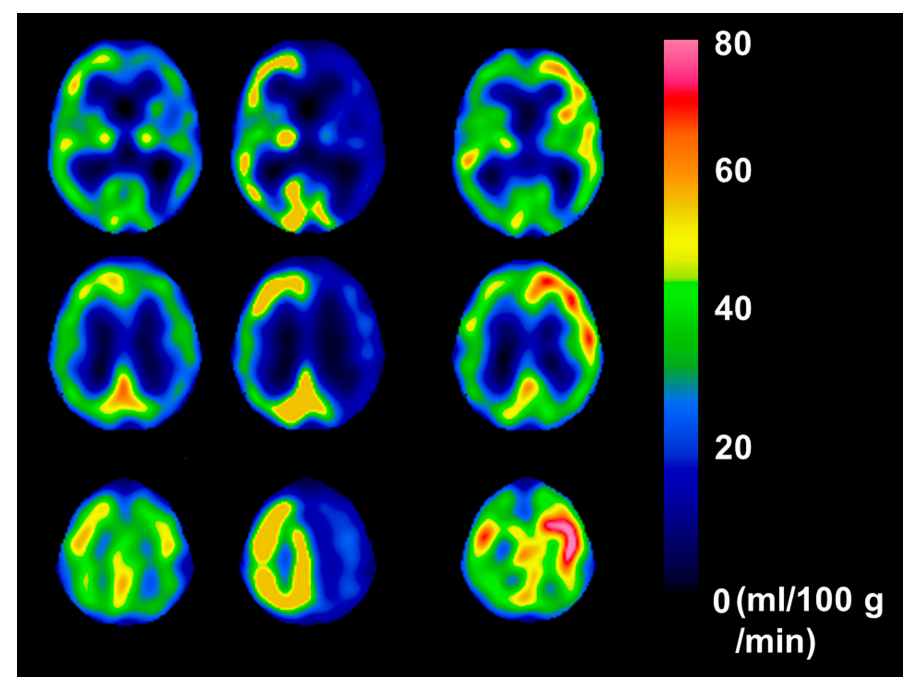

(A)

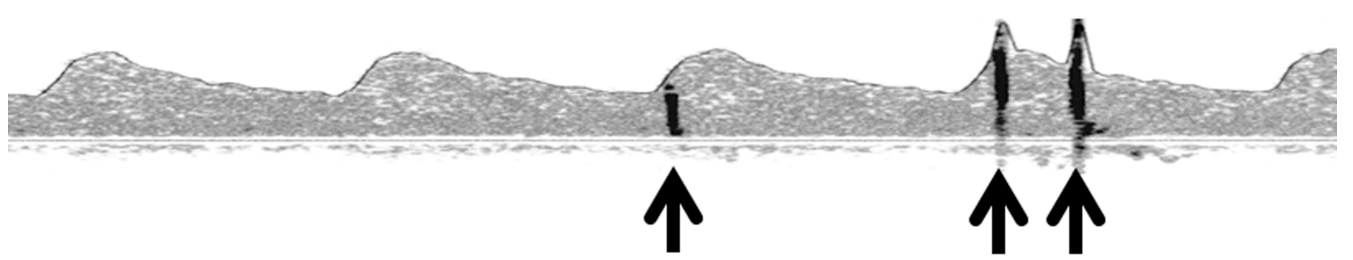

(B)

Figure 3. Cont. 


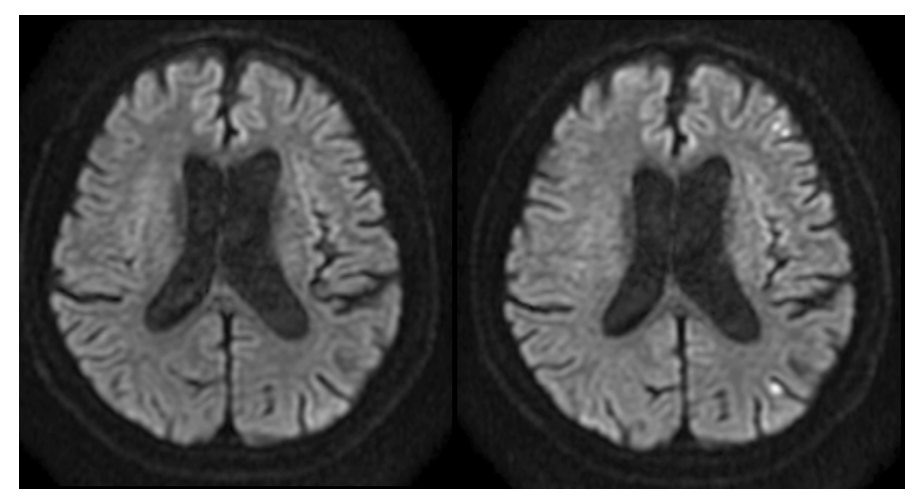

(C)

Figure 3. (A) Preoperative brain perfusion single-photon emission computed tomography in a 74-year-old man with symptomatic left internal carotid artery stenosis $(90 \%)$ shows reduced cerebral blood flow (left) and reduced cerebrovascular reactivity to acetazolamide (center) in the left cerebral hemisphere where hyperperfusion develops immediately after surgery (right); (B) Transcranial Doppler recording during exposure of the carotid arteries in the patient of Figure 3A shows three microembolic signals (arrows) in the power spectrum display of left middle cerebral artery blood flow. This patient had a total of 10 microembolic signals during exposure of the carotid arteries; (C) A diffusion-weighted image $6 \mathrm{~h}$ after surgery in the patient of Figure 3A,B shows development of new postoperative multiple high-intensity lesions in the left cerebral hemisphere (right) when compared with a preoperative image (left). These lesions did not change on diffusion-weighted imaging $24 \mathrm{~h}$ after surgery. This patient suffered slight motor weakness in the right upper extremity after recovery from general anesthesia, and this deficit resolved completely within $12 \mathrm{~h}$.

\section{Discussion}

\subsection{Findings}

The present study demonstrated that cerebral hyperperfusion after revascularization inhibits the development of cerebral ischemic lesions due to artery-to-artery emboli during carotid exposure in CEA for patients with preoperatively impaired cerebral hemodynamics, supporting the "impaired clearance of emboli" concept when broadening its interpretation.

\subsection{Reason of Patient Exclusion}

Hemodynamic cerebral ischemia due to hemispheric cerebral hypoperfusion during ICA clamping, as well as emboli from the surgical site, plays a significant role in the development of new ischemic lesions after CEA [11,23]. Intraoperative EEG monitoring is the most widely used and best documented method for the detection of hemispheric cerebral hypoperfusion due to carotid clamping [24]. To investigate the development of cerebral ischemic lesions caused by MES rather than by hemispheric cerebral hypoperfusion during ICA clamping, patients with EEG-defined hemispheric ischemia during ICA clamping were excluded from the present study.

\subsection{Data Interpretation}

In the present study, $44 \%$ of patients with preoperatively reduced CVR to acetazolamide showed cerebral hyperperfusion immediately after surgery. This incidence was comparable to a previous study [19-21]. All postoperative ischemic lesions on DWI that were newly developed in the cortex and/or white matter in the cerebral hemisphere ipsilateral to CEA were spotty, and their diameters were $1 \mathrm{~cm}$ or less. Furthermore, the duration of ICA clamping did not differ between patients with and without DWI-characterized postoperative cerebral ischemic lesions. Thus, these ischemic lesions were possibly due to artery-to-artery embolism rather than cerebral hemispheric ischemia during ICA clamping. More than $80 \%$ of patients with a combination of preoperatively reduced 
CVR to acetazolamide and MES during carotid exposure, when they did not exhibit postoperative cerebral hyperperfusion, developed DWI-characterized postoperative cerebral ischemic lesions, which corresponded with previous findings [14].

In the present study, preoperative CBF, preoperative CVR to acetazolamide, mean systolic blood pressure during carotid exposure, and interval from the first or last MES to ICA declamping did not differ between patients with and without DWI-characterized postoperative cerebral ischemic lesions. Thus, perfusion in the cerebral hemisphere ipsilateral to surgery during carotid exposure and the duration of cerebral ischemia caused by emboli until ICA declamping might be equivalent between these two subgroups of patients. The duration of ICA clamping also did not differ between them. Nevertheless, greater postoperative CBF or postoperative cerebral hyperperfusion (postoperative $\mathrm{CBF} \geqslant$ mean $+3.9 \mathrm{SD}$ of the control value) was associated with the absence of DWI-characterized postoperative cerebral ischemic lesions, and only $7 \%$ of patients with a combination of MES during carotid exposure and postoperative cerebral hyperperfusion developed these lesions. These findings suggested that blood flow that increased far beyond the normal level might clear cerebral emboli generated from the surgical site, inhibiting the development of ischemic lesions. These support the "impaired clearance of emboli" concept if the interpretation of this concept is broadened.

We have another hypothesis regarding the correlation between postoperative cerebral hyperperfusion and the development of ischemic lesions by emboli in patients with reduced CVR to acetazolamide. Reduced CVR to acetazolamide implies a chronic reduction in cerebral perfusion pressure and poor collateral blood flow [25-27]. When emboli generated from a lesion in the ICA acutely disturb blood flow in the cerebral artery, cerebral blood flow may be further decreased in the affected vascular territory with the pre-existing chronic reduction in cerebral perfusion pressure. However, if cerebral ischemic lesions have not yet formed between the onset of emboli and ICA declamping (the interval ranged from approximately $30 \mathrm{~min}$ to $60 \mathrm{~min}$ in the present study), hyperperfusion after ICA declamping may lead to an extreme increase in collateral blood flow to the affected vascular territory, inhibiting the postoperative development of new cerebral ischemic lesions.

\subsection{Future Directions}

The present study suggests that CBF greater than the normal level after declamping of the ICA can inhibit development of cerebral ischemic lesions due to emboli from the surgical site during exposure of the carotid arteries. On the other hand, postoperative cerebral hyperperfusion, which is defined as a postoperative CBF increase of $\geqslant 100 \%$ when compared to preoperative values, occasionally evolves into cerebral hyperperfusion syndrome, leading to intracerebral hemorrhage [15-18]. Strict postoperative control of blood pressure (systolic blood pressure $<90 \mathrm{mmHg}$ ) reportedly prevents the development of intracerebral hemorrhage $[16,20]$. Further, intraoperative monitoring of MCA flow velocity using TCD or regional cerebral oxygen saturation using near-infrared spectroscopy are reliable methods of identifying patients with cerebral hyperperfusion following declamping of the ICA during CEA [28,29]. On the basis of these findings, we propose a practical clinical algorithm to prevent development of embolic ischemic events and hyperperfusion-related hemorrhage in CEA: when the intraoperative monitoring suggests development of cerebral hyperperfusion following declamping of the ICA, the blood pressure should then be reduced; when the intraoperative monitoring suggests development of embolism from the surgical site during carotid exposure that is not accompanied by cerebral hyperperfusion, the blood pressure should be elevated above the preoperative value following declamping of the ICA. Further investigation to determine whether the latter procedure prevents development of cerebral ischemic lesions would be of benefit, although, in the present study, blood pressure was reduced for all patients regardless of the presence or absence of cerebral hyperperfusion after declamping of the ICA.

\subsection{Study Limitations}

Although TCD detects emboli generated from the surgical site of the carotid arteries as MES, it cannot provide information about the size and characteristics of each embolus, which may affect the 
development of postoperative cerebral ischemic lesions. The present results did not take into account these two factors.

\section{Materials and Methods}

\subsection{Subjects}

The present study was designed as a prospective, observational study. This study was approved by the Regional Ethical Board in Iwate Medical University (H22-3) and was in compliance with the Helsinki Declaration, and written, informed consent was obtained from all patients or their next of kin prior to participation.

Of symptomatic or asymptomatic patients with ipsilateral ICA stenosis $\geqslant 70 \%$, as per the North American Symptomatic Carotid Endarterectomy Trial [30], on angiography/arterial catheterization, and useful residual function (modified Rankin scale score 0,1 , or 2) who were scheduled for CEA of the carotid bifurcation, those who satisfied the following inclusion criteria were prospectively selected for the present study: having preoperatively reduced CVR to acetazolamide according to the methods described below (see "4.2. CBF Measurements" section); undergoing CEA; and having MES during exposure of the carotid arteries under reliable TCD monitoring according to the methods described below (see "4.3. TCD Monitoring" section). Patients who showed electroencephalography (EEG)-defined cerebral hemispheric ischemia during ICA clamping according to the methods described below (see "4.5. Preoperative, Intraoperative, and Postoperative Management" section) were excluded from the present study.

\subsection{CBF Measurements}

CBF was assessed using $\left[{ }^{123} \mathrm{I}\right] \mathrm{N}$-isopropyl-p-iodoamphetamine (IMP) and SPECT with a ring-type scanner (Headtome-SET 080; Shimadzu, Kyoto, Japan) within 14 days before and immediately after CEA. CBF measurement with acetazolamide challenge was also performed before CEA. The ${ }^{123}$ I]IMP SPECT study with and without acetazolamide challenge was performed as described previously [31,32]. After a $1 \mathrm{~min}$ intravenous infusion of $222 \mathrm{MBq}$ of $\left[{ }^{123} \mathrm{I}\right] \mathrm{IMP}$ ( $5 \mathrm{~mL}$ volume) at a constant rate of $5 \mathrm{~mL} / \mathrm{min}$ and a $1 \mathrm{~min}$ infusion of physiologic saline at the same rate, data acquisition was performed at a midscan time of $30 \mathrm{~min}$ after the [ $\left.{ }^{123} \mathrm{I}\right] \mathrm{IMP}$ administration for a scan duration of $20 \mathrm{~min}$. At $10 \mathrm{~min}$ after the beginning of the $\left[{ }^{123} \mathrm{I}\right] \mathrm{IMP}$ infusion, arterial blood $(1 \mathrm{~mL})$ was taken from the brachial artery. The whole-blood radioactivity of each blood sample obtained was measured using a well counter that was cross-calibrated to the SPECT scanner. All reconstructed SPECT images were corrected for the radioactive decay of ${ }^{123} \mathrm{I}$ back to the $\left[{ }^{123} \mathrm{I}\right] \mathrm{IMP}$ injection start time, normalized by the data collection time and cross-calibrated to the well counter system. The CBF images were calculated according to the $\left[{ }^{123}\right.$ I]IMP-autoradiography method [31,32]. The whole-blood radioactivity counts of the single blood sample were referred to the standard input function.

All SPECT images were transformed into standard brain size and shape by linear and nonlinear transformations using statistical parametric mapping 2 software for anatomical standardization [33]. A three-dimensional stereotactic region-of-interest (ROI) template was used to automatically place 318 constant ROIs in both cerebral and cerebellar hemispheres [34]. ROIs were grouped into 10 segments (callosomarginal, pericallosal, precentral, central, parietal, angular, temporal, posterior, hippocampal, and cerebellar) in each hemisphere according to the arterial supply. Five (precentral, central, parietal, angular, and temporal) of these 10 segments were combined and defined as an ROI perfused by the middle cerebral artery (MCA) (Figure 4).

The mean value of all pixels in the MCA ROI in the cerebral hemisphere ipsilateral to CEA was calculated. Preoperative CVR to acetazolamide in the cerebral hemisphere ipsilateral to CEA was calculated as follows: $\mathrm{CVR}(\%)=[(\mathrm{CBF}$ with acetazolamide challenge $-\mathrm{CBF}$ at the resting state $) / \mathrm{CBF}$ at the resting state] $\times 100$. For CBF in the resting state and CVR to acetazolamide, data described previously ((mean $\pm \mathrm{SD}), 35.9 \pm 4.4 \mathrm{~mL} / 100 \mathrm{~g} / \mathrm{min}$ and $36.8 \% \pm 9.2 \%$, respectively) were used as 
control values, and decreased CVR to acetazolamide was defined as less than mean -2 SD of the control value (18.4\%) [31]. In each patient, cerebral hyperperfusion was defined as a postoperative CBF increase of $\geqslant 100 \%$ (i.e., a doubling) when compared to preoperative values in the MCA ROI ipsilateral to the side of surgery [20].

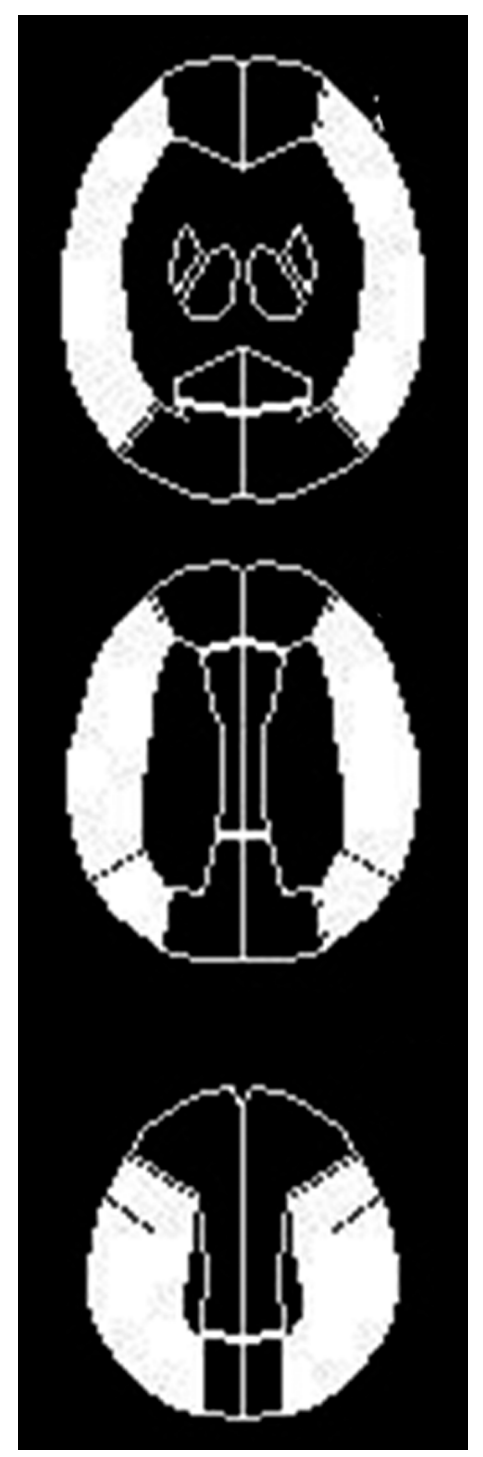

Figure 4. Diagrams show the regions of interests (ROIs) for a three-dimensional, stereotactic ROI template to automatically place constant ROIs on brain perfusion single-photon emission computed tomography images. White ROIs indicate middle cerebral artery territories (precentral, central, parietal, angular, and temporal).

\subsection{Transcranial Doppler (TCD) Monitoring}

TCD was performed using a PIONEER TC2020 system (EME, Uberlingen, Germany; software version 2.50, $2 \mathrm{MHz}$ probe; diameter, $1.5 \mathrm{~cm}$; insonation depth, $40-66 \mathrm{~mm}$; scale, -100 and $+150 \mathrm{~cm} / \mathrm{s}$; sample volume, $2 \mathrm{~mm}$; 64 point fast Fourier transform; fast Fourier transform length, $2 \mathrm{~mm}$; fast Fourier transform overlap, 60\%; high-pass filter, $100 \mathrm{~Hz}$; detection threshold, $9 \mathrm{~dB}$; minimum increase time, $10 \mathrm{~ms}$ ) for insonation of the MCA ipsilateral to the carotid artery undergoing CEA. TCD data were stored on a hard disk using a coding system and later analyzed manually by a clinical neurophysiologist who was blinded to patient information. MES were identified during exposure of the carotid arteries (from skin incision to ICA clamping) according to the recommended guidelines [35]. 


\subsection{Magnetic Resonance Imaging}

DWI was performed using a $1.5 \mathrm{~T}$ whole-body imaging system (Signa MR/I; GE Healthcare, Milwaukee, WI, USA) within three days before and $24 \mathrm{~h}$ after surgery.

A neuroradiologist who was blinded to patient clinical information analyzed the images and determined whether new ischemic lesions had developed postoperatively.

\subsection{Preoperative, Intraoperative, and Postoperative Management}

Blood pressure was measured at the upper arm using an automatic sphygmomanometer with the oscillometric method, and mean systolic blood pressure in the morning for the three days before surgery was defined as the preoperative value for each patient. Patients received medications including antihypertensive and antidiabetic drugs and statins until the evening of the day before CEA was performed. All patients received a single antiplatelet drug until the morning of the day on which CEA was performed. For all patients, surgery was conducted under general anesthesia, which was induced with etomidate/fentanyl and maintained with $\mathrm{O}_{2}$ /propofol. A bolus of heparin (5000 international units) was given prior to ICA clamping. Blood pressure was measured in the same fashion as preoperatively every $5 \mathrm{~min}$ throughout surgery. The EEG was recorded, and a clinical neurophysiologist monitored the recordings continuously during the surgical procedure. The presence of unilateral or bilateral decreases of alpha and beta activity during ICA clamping, with or without simultaneous increases of theta or delta activity, was defined as development of cerebral hemispheric ischemia by the clinical neurophysiologist [24]. In this situation, an intraluminal shunt was introduced. From declamping of the ICA to the third postoperative day, attempts were made to reduce systolic blood pressure to below $90 \%$ of the preoperative value using intravenous injection of the calcium antagonist nicardipine. Blood pressure was measured in the same fashion as preoperatively every $1 \mathrm{~h}$ until $24 \mathrm{~h}$ after surgery. When systolic blood pressure was $<90 \%$ of the preoperative value at a blood pressure-measured point, the point was defined as having successfully controlled blood pressure. Patients received the same drugs as preoperative medications from the second postoperative day.

\subsection{Statistical Analysis}

Data are expressed as means \pm SD. The relationship between each variable and DWI-characterized postoperative cerebral ischemic lesions was evaluated by univariate analysis using the Mann-Whitney $\mathrm{U}$ test or the $\chi^{2}$ test. Hypertension was defined as preoperative systolic blood pressure $\geqslant 140 \mathrm{mmHg}$, preoperative diastolic blood pressure $\geqslant 90 \mathrm{mmHg}$ or preoperatively receiving antihypertensive drugs; diabetes mellitus was defined as preoperative hemoglobin $\mathrm{A} 1 \mathrm{c} \geqslant 6.5 \%$ or preoperatively receiving antidiabetic drugs; dyslipidemia was defined as preoperative plasma low density lipoprotein (LDL) cholesterol $\geqslant 140 \mathrm{mg} / \mathrm{dL}$, preoperative plasma high density lipoprotein (HDL) cholesterol $<40 \mathrm{mg} / \mathrm{dL}$, preoperative plasma triglyceride $\geqslant 150 \mathrm{mg} / \mathrm{dL}$, or preoperatively receiving statins. Multivariate statistical analysis of factors related to DWI-characterized postoperative cerebral ischemic lesions was also performed using a logistic regression model. Variables with $p<0.2$ on univariate analyses were selected for analysis in the final model. Differences were deemed significant for values of $p<0.05$.

\section{Conclusions}

The present study demonstrated that cerebral hyperperfusion after revascularization inhibits the development of cerebral ischemic lesions due to artery-to-artery emboli during carotid exposure in CEA for patients with preoperatively impaired cerebral hemodynamics, supporting the "impaired clearance of emboli" concept when its interpretation is broadened.

Acknowledgments: The author (Kuniaki Ogasawara) disclosed receipt of the following financial support for the research, authorship, and/or publication of this article: Strategic Medical Science Research from the Ministry of Education, Culture, Sports, Science and Technology of Japan, Grant Number S1491001; Scientific Research from Japan Society for the Promotion of Science, Grant Number JP15K10313. 
Author Contributions: Kentaro Fujimoto and Kuniaki Ogasawara conceived and designed the study; Yoshiyasu Matsumoto, Kohki Oikawa and Kazunori Terasaki performed measurements and analyses of brain perfusion; Masakazu Kobayashi performed measurements and analyses of microembolic signals on transcranial Doppler; Shunrou Fujiwara statically analyzed the data; Jun-ichi Nomura, Yasuyoshi Shimada and Kenji Yoshida critically revised the manuscript and helped with results interpretation. Kentaro Fujimoto and Kuniaki Ogasawara wrote the paper.

Conflicts of Interest: The author (Kuniaki Ogasawara) declared the following potential conflicts of interest with respect to the research, authorship, and/or publication of this article: Consigned research fund $(3,150,000$ yen) from Nihon Medi-Physics Co., Ltd.

$\begin{array}{ll}\text { Abbreviations } \\ \text { CEA } & \text { Carotid endarterectomy } \\ \text { TCD } & \text { Transcranial Doppler } \\ \text { MCA } & \text { Middle cerebral artery } \\ \text { MES } & \text { Microembolic signals } \\ \text { DWI } & \text { Diffusion-weighted imaging } \\ \text { CVR } & \text { Cerebrovascular reactivity } \\ \text { CBF } & \text { Cerebral blood flow } \\ \text { SPECT } & \text { Single-photon emission computed tomography } \\ \text { ICA } & \text { Internal carotid artery } \\ \text { EEG } & \text { Electroencephalography } \\ \text { IMP } & \text { [ }{ }^{123} \text { I]N-isopropyl- } p \text {-iodoamphetamine } \\ \text { ROI } & \text { Region-of-interest } \\ \text { SD } & \text { Standard deviation }\end{array}$

\section{References}

1. Caplan, L.R.; Hennerici, M. Impaired clearance of emboli (washout) is an important link between hypoperfusion, embolism, and ischemic stroke. Arch. Neurol. 1998, 55, 1475-1482. [CrossRef]

2. Caplan, L.R.; Wong, K.S.; Gao, S.; Hennerici, M.G. Is hypoperfusion an important cause of strokes? If so, how? Cerebrovasc. Dis. 2006, 21, 145-153. [CrossRef] [PubMed]

3. Wong, K.S.; Gao, S.; Chan, Y.L.; Hansberg, T.; Lam, W.W.; Droste, D.W.; Kay, R.; Ringelstein, E.B. Mechanisms of acute cerebral infarctions in patients with middle cerebral artery stenosis: A diffusion-weighted imaging and microemboli monitoring study. Ann. Neurol. 2002, 52, 74-81. [CrossRef] [PubMed]

4. Schreiber, S.; Serdaroglu, M.; Schreiber, F.; Skalej, M.; Heinze, H.J.; Goertler, M. Simultaneous occurrence and interaction of hypoperfusion and embolism in a patient with severe middle cerebral artery stenosis. Stroke 2009, 40, e478-e480. [CrossRef] [PubMed]

5. Orlandi, G.; Fanucchi, S.; Gallerini, S.; Sonnoli, C.; Cosottini, M.; Puglioli, M.; Sartucci, F.; Murri, L. Impaired clearance of microemboli and cerebrovascular symptoms during carotid stenting procedures. Arch. Neurol. 2005, 62, 1208-1211. [CrossRef] [PubMed]

6. Spencer, M.P. Transcranial Doppler monitoring and causes of stroke from carotid endarterectomy. Stroke 1997, 28, 685-691. [CrossRef] [PubMed]

7. Ackerstaff, R.G.; Moons, K.G.; van de Vlasakker, C.J.; Moll, F.L.; Vermeulen, F.E.; Algra, A.; Spencer, M.P. Association of intraoperative transcranial doppler monitoring variables with stroke from carotid endarterectomy. Stroke 2000, 31, 1817-1823. [CrossRef] [PubMed]

8. Wolf, O.; Heider, P.; Heinz, M.; Poppert, H.; Sander, D.; Greil, O.; Weiss, W.; Hanke, M.; Eckstein, H.H. Microembolic signals detected by transcranial Doppler sonography during carotid endarterectomy and correlation with serial diffusion-weighted imaging. Stroke 2004, 35, e373-e375. [CrossRef] [PubMed]

9. Gavrilescu, T.; Babikian, V.L.; Cantelmo, N.L.; Rosales, R.; Pochay, V.; Winter, M. Cerebral microembolism during carotid endarterectomy. Am. J. Surg. 1995, 170, 159-164. [CrossRef]

10. Rothwell, P.M.; Eliasziw, M.; Gutnikov, S.A.; Fox, A.J.; Taylor, D.W.; Mayberg, M.R.; Warlow, C.P.; Barnett, H.J. Analysis of pooled data from the randomised controlled trials of endarterectomy for symptomatic carotid stenosis. Lancet 2003, 361, 107-116. [CrossRef]

11. Verhoeven, B.A.; de Vries, J.P.; Pasterkamp, G.; Ackerstaff, R.G.; Schoneveld, A.H.; Velema, E.; de Kleijn, D.P.; Moll, F.L. Carotid atherosclerotic plaque characteristics are associated with microembolization during carotid endarterectomy and procedural outcome. Stroke 2005, 36, 1735-1740. [CrossRef] [PubMed] 
12. Gaunt, M.E.; Martin, P.J.; Smith, J.L.; Rimmer, T.; Cherryman, G.; Ratliff, D.A.; Bell, P.R.; Naylor, A.R. Clinical relevance of intraoperative embolization detected by transcranial Doppler ultrasonography during carotid endarterectomy: A prospective study of 100 patients. Br. J. Surg. 1994, 81, 1435-1439. [CrossRef] [PubMed]

13. Jansen, C.; Ramos, L.M.; van Heesewijk, J.P.; Moll, F.L.; van Gijn, J.; Ackerstaff, R.G. Impact of microembolism and hemodynamic changes in the brain during carotid endarterectomy. Stroke 1994, 25, 992-997. [CrossRef] [PubMed]

14. Aso, K.; Ogasawara, K.; Sasaki, M.; Kobayashi, M.; Suga, Y.; Chida, K.; Otawara, Y.; Ogawa, A. Preoperative cerebrovascular reactivity to acetazolamide measured by brain perfusion SPECT predicts development of cerebral ischemic lesions caused by microemboli during carotid endarterectomy. Eur. J. Nucl. Med. Mol. Imaging 2009, 36, 294-301. [CrossRef] [PubMed]

15. Bernstein, M.; Fleming, J.F.; Deck, J.H. Cerebral hyperperfusion after carotid endarterectomy: A cause of cerebral hemorrhage. Neurosurgery 1984, 15, 50-56. [CrossRef] [PubMed]

16. Ogasawara, K.; Sakai, N.; Kuroiwa, T.; Hosoda, K.; Iihara, K.; Toyoda, K.; Sakai, C.; Nagata, I.; Ogawa, A. Intracranial hemorrhage associated with cerebral hyperperfusion syndrome following carotid endarterectomy and carotid artery stenting: Retrospective review of 4494 patients. J. Neurosurg. 2007, 107, 1130-1136. [CrossRef] [PubMed]

17. Piepgras, D.G.; Morgan, M.K.; Sundt, T.M., Jr.; Yanagihara, T.; Mussman, L.M. Intracerebral hemorrhage after carotid endarterectomy. J. Neurosurg. 1988, 68, 532-536. [CrossRef] [PubMed]

18. Sundt, T.M., Jr.; Sharbrough, F.W.; Piepgras, D.G.; Kearns, T.P.; Messick, J.M., Jr.; O'Fallon, W.M. Correlation of cerebral blood flow and electroencephalographic changes during carotid endarterectomy, with results of surgery and hemodynamics of cerebral ischemia. Mayo Clin. Proc. 1981, 56, 533-543. [CrossRef] [PubMed]

19. Hosoda, K.; Kawaguchi, T.; Shibata, Y.; Kamei, M.; Kidoguchi, K.; Koyama, J.; Fujita, S.; Tamaki, N. Cerebral vasoreactivity and internal carotid artery flow help to identify patients at risk for hyperperfusion after carotid endarterectomy. Stroke 2001, 32, 1567-1573. [CrossRef] [PubMed]

20. Ogasawara, K.; Yukawa, H.; Kobayashi, M.; Mikami, C.; Konno, H.; Terasaki, K.; Inoue, T.; Ogawa, A. Prediction and Monitoring of cerebral hyperperfusion after carotid endarterectomy by using single-photon emission computerized tomography scanning. J. Neurosurg. 2003, 99, 504-510. [CrossRef] [PubMed]

21. Yoshimoto, T.; Houkin, K.; Kuroda, S.; Abe, H.; Kashiwaba, T. Low cerebral blood flow and perfusion reserve induce hyperperfusion after surgical revascularization: Case reports and analysis of cerebral hemodynamics. Surg. Neurol. 1997, 48, 132-139. [CrossRef]

22. Yadav, J.S.; Wholey, M.H.; Kuntz, R.E.; Fayad, P.; Katzen, B.T.; Mishkel, G.J.; Bajwa, T.K.; Whitlow, P.; Strickman, N.E.; Jaff, M.R.; et al. Protected carotid-artery stenting versus endarterectomy in high-risk patients. N. Engl. J. Med. 2004, 351, 1493-1501. [CrossRef] [PubMed]

23. Van der Schaaf, I.C.; Horn, J.; Moll, F.L.; Ackerstaff, R.G. Transcranial Doppler monitoring after carotid endarterectomy. Ann. Vasc. Surg. 2005, 19, 19-24. [CrossRef] [PubMed]

24. Rutgers, D.R.; Blankensteijn, J.D.; van der Grond, J. Preoperative MRA flow quantification in CEA patients: Flow differences between patients who develop cerebral ischemia and patients who do not develop cerebral ischemia during cross-clamping of the carotid artery. Stroke 2000, 31, 3021-3028. [CrossRef] [PubMed]

25. Grubb, R.L., Jr.; Derdeyn, C.P.; Fritsch, S.M.; Carpenter, D.A.; Yundt, K.D.; Videen, T.O.; Spitznagel, E.L.; Powers, W.J. Importance of hemodynamic factors in the prognosis of symptomatic carotid occlusion. JAMA 1998, 280, 1055-1060. [CrossRef] [PubMed]

26. Kuroda, S.; Houkin, K.; Kamiyama, H.; Mitsumori, K.; Iwasaki, Y.; Abe, H. Long-term prognosis of medically treated patients with internal carotid or middle cerebral artery occlusion: Can acetazolamide test predict it? Stroke 2001, 32, 2110-2116. [CrossRef] [PubMed]

27. Schmiedek, P.; Piepgras, A.; Leinsinger, G.; Kirsch, C.M.; Einhüpl, K. Improvement of cerebrovascular reserve capacity by EC-IC arterial bypass surgery in patients with ICA occlusion and hemodynamic cerebral ischemia. J. Neurosurg. 1994, 81, 236-244. [CrossRef] [PubMed]

28. Ogasawara, K.; Konno, H.; Yukawa, H.; Endo, H.; Inoue, T.; Ogawa, A. Transcranial regional cerebral oxygen saturation monitoring during carotid endarterectomy as a predictor of postoperative hyperperfusion. Neurosurgery 2003, 53, 309-315. [CrossRef] [PubMed]

29. Ogasawara, K.; Inoue, T.; Kobayashi, M.; Endo, H.; Yoshida, K.; Fukuda, T.; Terasaki, K.; Ogawa, A. Cerebral hyperperfusion following carotid endarterectomy: Diagnostic utility of intraoperative transcranial Doppler ultrasonography compared with single-photon emission computed tomography study. AJNR Am. J. Neuroradiol. 2005, 26, 252-257. [PubMed] 
30. North American Symptomatic Carotid Endarterectomy Trial Collaborators. Beneficial effect of carotid endarterectomy in symptomatic patients with high-grade carotid stenosis. N. Engl. J. Med. 1991, 325, 445-453.

31. Ogasawara, K.; Ito, H.; Sasoh, M.; Okuguchi, T.; Kobayashi, M.; Yukawa, H.; Terasaki, K.; Ogawa, A. Quantitative measurement of regional cerebrovascular reactivity to acetazolamide using ${ }^{123} \mathrm{I}-\mathrm{N}$-isopropylp-iodoamphetamine autoradiography with SPECT: Validation study using $\mathrm{H}_{2}{ }^{15} \mathrm{O}$ with PET. J. Nucl. Med. 2003, 44, 520-525. [PubMed]

32. Iida, H.; Itoh, H.; Nakazawa, M.; Hatazawa, J.; Nishimura, H.; Onishi, Y.; Uemura, K. Quantitative mapping of regional cerebral blood flow using iodine-123-IMP and SPECT. J. Nucl. Med. 1994, 35, 2019-2030. [PubMed]

33. Nishimiya, M.; Matsuda, H.; Imabayashi, E.; Kuji, I.; Sato, N. Comparison of SPM and NEUROSTAT in voxelwise statistical analysis of brain SPECT and MRI at the early stage of Alzheimer's disease. Ann. Nucl. Med. 2008, 22, 921-927. [CrossRef] [PubMed]

34. Takeuchi, R.; Matsuda, H.; Yoshioka, K.; Yonekura, Y. Cerebral blood flow SPET in transient global amnesia with automated ROI analysis by 3DSRT. Eur. J. Nucl. Med. Mol. Imaging 2004, 31, 578-589. [CrossRef] [PubMed]

35. Consensus Committee of the Ninth International Cerebral Hemodynamic Symposium. Basic identification criteria of Doppler microembolic signals. Stroke 1995, 26, 1123. [CrossRef]

(c) 2016 by the authors; licensee MDPI, Basel, Switzerland. This article is an open access article distributed under the terms and conditions of the Creative Commons Attribution (CC-BY) license (http://creativecommons.org/licenses/by/4.0/). 